\title{
Von Willebrand factor, ADAMTS13 and Neutrophil Extracellular Traps: allies in cancer-associated thrombosis and tumor progression?
}

\author{
Marcello Monti* \\ Department of Clinical Medicine and Surgery, "Federico II” University, Naples, Italy
}

\begin{abstract}
Cancer and thrombotic events are strongly associated and von Willebrand factor (VWF) plays a key role in these biological processes. Degradation by ADAMTS13 of ultralarge VWF multimers (UL-VWF) enriched in VWF is crucial to avoid their accumulation in blood resulting in thrombosis. Neutrophil Extracellular Traps (NETs) represent a relatively new mechanism involved in cancer-associated thrombosis and metastases. Since levels of plasma VWF are significantly elevated in cancer patients and NETs DNA positively correlates with VWF and negatively with levels of ADAMTS13, here is highlighted how VWF, ADAMTS 13 and NETs can be correlated in cancer-associated thrombosis and tumor progression.
\end{abstract}

Abbreviations: NETs: Neutrophil Extracellualr Traps; VWF: von Willebrand factor; UL-VWF: Ultralarge VWF multimers, VTE: venous thromboembolism

\section{Introduction}

A 4- to 7-fold increased risk of venous thromboembolism (VTE) has been reported for cancer patients as compared to general population and VTE is the second most prevalent cause of death in cancer [1-3]. Patients with metastatic disease have a higher risk of VTE than those with localized tumors [4-6] and platelets play a key role in cancer development and they can interact with metastasizing cancer cells becoming deadly allies [7]. Tumor cell-induced platelet aggregation (TCIPA) is a multistep process in which tumor cells can activate and aggregate platelets leading in the blood stream to the initiation of thrombus formation as well as metastatic cascade [8]. In in vitro model system, platelet rich plasma (PRP) of cancer patients resulted in enhanced aggregation by $127 \%$ compared to healthy control PRP [9]. From a molecular point of view, it's an old notion that cancer cells have also been widely reported to secrete platelet agonists such as ADP and thromboxane A2 to induce two different pathways for platelet aggregation $[10,11]$ and conversely platelet receptor P2Y12 was found to influence mechanisms leading to cancer progression as well, mainly by regulating tumor cell/platelet interaction and angiogenesis [12].

Besides, platelets can protect metastatic tumor cells from immune surveillance and help them to attach at the endothelium upon their arrest at metastatic sites [13]. Platelets and endothelial cells with their adhesion properties may facilitate metastasis by augmenting tumor cell extravasation which is favoured by irreversible and complete platelet aggregation achieved after ATP secretion by platelets granules [14]. In this scenario, Wahrenbrock $\mathrm{M}$, et al. demonstrated in vivo that tumor metastases were reduced in mice lacking the vascular adhesion molecules P- and L-selectin [15] and vascular endothelial growth factor (VEGF) released by a-granules of activated platelet was able to promote vasculogenesis in the circulation of patients with cancer $[16,17]$.

\section{Von Willebrand factor (VWF) and ADAMTS13 in thrombosis and cancer}

Endothelial cells, megakaryocytes and platelets synthesize von Willebrand factor (VWF), the largest multimeric glycoprotein in human blood involved in regulating hemostasis [18-20]. Circulating VWF connect at the site of vascular injury in the subendothelial matrix by binding the platelet GP Ib-IX-V complex, promoting platelet accumulation (i.e. adhesion, activation and aggregation) in the classical first wave of hemostasis or primary hemostasis [21-23].

After being synthesized, pro-VWF monomers dimerize through C-terminal disulfide bonds and a variable number of dimers then multimerize through N-terminal disulfide bonds [24,25]. Newly synthesized VWF multimers are either constitutively released or stored in the Weibel-Palade bodies of endothelial cells and in the a-granules of megakaryocytes and platelets before to be constitutively secreted in ultralarge VWF multimers (UL-VWF), which are enriched in VWF and hyperreactive in their ability to bind platelets $[22,26,27]$. UL-VWF are typically cleaved between tyrosine 842 and methionine 843 amino acid residues in the A2 domain of VWF in smaller fragments of 176 and $140-\mathrm{kDa}$ by VWF-cleaved protease also identified as ADAMTS13 (a disintegrin-like and metalloprotease with thrombospondin type 1 motif 13), a $\mathrm{Zn2+/Ca2+-dependent} \mathrm{metalloprotease} \mathrm{[28-31]} \mathrm{essential}$ for the physiological vascular homeostasis obtained upon VWF proteolysis [32]. The detection of VWF plasma level is mainly a reliable marker of thrombosis and thromboembolism [33,34]. Moreover, levels of plasma VWF are significantly elevated in cancer patients $[35,36]$ and associated not only with cancer-associated thrombosis [37], but

${ }^{\star}$ Correspondence to: Marcello Monti, Department of Clinical Medicine and Surgery, "Federico II" University, Naples, Italy, E-mail: marcello.monti@unina.it Key words: NETs, VWF, ADAMTS13, cancer, thrombosis

Received: April 19, 2020; Accepted: April 27, 2020; Published: April 30, 2020 
also with the grade of malignancy, occurrence of metastases and poor prognosis [9,38-40]. Undigested UL-VWF were observed in patients with disseminated tumors and they result from deficient ADAMTS13 protease activity. Interestingly, the clinical presence and absence of tumor metastases correlated significantly with ADAMTS13 enzymatic activities for $<15 \%$ and $>88 \%$, respectively [ 41 ]. Some single nucleotide polymorphisms (SNP) of ADAMTS13 were associated with a reduced protease activity. In particular, the polymorphisms Val154Ile, Asp187His, Arg421Cys, Tyr603Cys resulted in 15\%, 19\%, 24\% and $28 \%$, respectively [42]. Another study confirmed that another SNP, the P475S mutation, led to a dramatic decreases in VWF-cleaved protease activity [43]. Notably, reduced ADAMTS13 enzymatic activity as well as high plasma VWF/ADAMTS13 ratio may serve as an independent predictive factor for mortality in patients with advanced Non-Small Cell Lung Cancer (NSCLC) [44] .

\section{Neutrophil Extracellular Traps (NETs) in thrombus formation and in cancer dissemination}

Neutrophil Extracellular Traps (NETs) formation in a process termed NETosis is emerged as a relevant process involved in thrombosis and cancer progression. Discovered in 2004 by Brinkamnn and colleagues [45], these traps composed by decondensed chromatin and extracellular DNA represent an alternative to phagocytosis, by which neutrophils are able to kill different microorganisms such as virus, bacteria, and fungi through the action of myeloperoxidase, neutrophil elastase/histones and calprotectin, respectively $[46,47]$.

Interestingly, a crucial role for NETs was demonstrated in promoting thrombosis [48] since NETs can provide a scaffold for platelet and red blood cell adhesion and aggregation thus enhancing coagulation $[49,50]$. All the major constituents of NETs that is extracellular DNA, histones and protease all have procoagulant properties. Nucleic acids activate coagulation through RNA binding to factor XII and XI in the intrinsic pathway as well as histones increase thrombin generation in a platelet-dependent manner promoting coagulation [51-53].

Several plasma protein important for platelet adhesion and thrombus propagation such as fibronectin and VWF may bind to NETs [51]. In these respect, it was demonstrated that both these proteins are key components of NETs not derived from plasma. In a murine model of deep vein thrombosis (DVT), it was observed that citrullinated histone H3 (citH3) by Peptidyl arginine deiminase 4 (PAD4) in NETs colocalized with VWF, suggesting that this VWF and NETs create a complex favoring thrombus growth and stabilization [49].

Furthermore, the UL-VWF adhered to the endothelium can bind and immobilize the DNA released by NETs acting as a linker between leukocyte adhesion to the endothelium and supporting leukocyte extravasation and inflammation $[54,55]$.

Monti, et al. discovered fibronectin as a endogenous component of NETs [56]. This finding opened an interesting setting in various biological processes in which NETs are involved since the fibronectin in the web-like structure of NETs provides specific binding sites for several integrins expressed on the plasma membrane of different cell types, such as platelets, endothelial cells and cancer cells [56]. In this regard, NETs have a key role in cancer progression [57] and the presence of fibronectin in the NETs structure may explain the adhesion of cancer cells of different origin by the expression of RGDbinding integrins (specially $\alpha 5 \beta 1$ and $\alpha v \beta 3$ ) mediating the entrapment onto NETs allowing the first step of the metastatic cascade [58].
In preclinical models of lung and colon cancer, it was demonstrated that NETs functionally regulated disease progression and that blocking NETosis through multiple strategies significantly inhibited spontaneous metastasis to the lung and liver [59]. Moreover, in a murine model of infection using cecal ligation and puncture, NETs deposition drove the entrapment of circulating lung carcinoma cells associated with increased formation of hepatic micrometastases at 48 hours after tumor cell injection. These effects were abrogated by NETs inhibition with DNAse or a neutrophil elastase inhibitor [60]. Neutrophils from mice with chronic myelogenous leukemia were prone to generate extracellular DNA traps and extracellular chromatin released through NETs formation was demonstrated to be the source for cancer-associated thrombosis [61].

Since the regulation in size of UL-VWF multimers by ADAMTS13 is a relevant mechanism to control invasion of PMNs and higher perivascular leukocyte infiltration was observed in ADAMTS13 $3^{-/}$mice [62], it would be interesting study the correlation between ADAMTS-13 genetic polymorphisms and its reduced enzymatic activity. This should imply accumulation of UL-VWF multimers and also an improved leukocyte infiltration more prone to NETosis. In turn these events could drive NETs-dependent cancer-associated thrombosis and tumor progression.

\section{Conclusion}

In the tumor microenvironment, a clear correlation between NETs and VWF is established and the optimal strategy would be a therapy able to target NETs and inhibit its dual role as fuel of the the metastatic dissemination and as trigger of thrombus formation after entrapping cancer cells in the blood vessels lumen.

\section{Competing Interests}

No conflicts of interest exist.

\section{References}

1. Fernandes CJ, Morinaga LTK, Alves JL Jr, Castro MA, Calderaro D, et al. (2019) Cancer-associated thrombosis: the when, how and why. Eur Respir Rev 28. [Crossref]

2. Noble S, Pasi J (2010) Epidemiology and Pathophysiology of Cancer-Associated Thrombosis. Br J Cancer 1: S2-S9.

3. Sheth RA, Niekamp A, Quencer KB, Shamoun F, Knuttinen MG, et al. (2017) Thrombosis in Cancer Patients: Etiology, Incidence, and Management. Cardiovasc Diagn Ther 7: S178-S185.

4. Hisada Y, Geddings JE, Ay C, Mackman N, et al. (2015) Venous thrombosis and cancer: from mouse models to clinical trials. J Thromb Haemost 13: 1372-1382. [Crossref]

5. Razak NBA, Jones G, Bhandari M, Berndt MC, Metharom P (2018) Cancer-Associated Thrombosis: An Overview of Mechanisms, Risk Factors, and Treatment. Cancers (Basel) 10: 380 .

6. Riedl JM, Posch F, Bezan A, Szkandera J, Smolle MA, et al. (2017) Patterns of venous thromboembolism risk in patients with localized colorectal cancer undergoing adjuvant chemotherapy or active surveillance: an observational cohort study. BMC Cancer 17: 415. [Crossref]

7. Erpenbeck L, Schön MP (2010) Deadly Allies: The Fatal Interplay Between Platelets and Metastasizing Cancer Cells. Blood 115: 3427-36.

8. Bastida E, Almirall L, Ordinas A (1987) Tumor-cell-induced Platelet Aggregation Is a Glycoprotein-Dependent and Lipoxygenase-Associated Process. Int J Cancer 39: 760-3.

9. Oleksowicz L1, Bhagwati N, DeLeon-Fernandez M (1999) Deficient activity of von Willebrand's factor-cleaving protease in patients with disseminated malignancies. Cancer Res 59: 2244-2250. [Crossref]

10. 10. Camez A, Dupuy E, Bellucci S, Calvo F, Bryckaert MC, et al. (1986) Human Platelet-Tumor Cell Interactions Vary With the Tumor Cell Lines. Invasion Metastasis 6: $321-334$. 
11. Honn KV, Steinert BW, Moin K, Onoda JM, Taylor JD, et al. (1987) The Role of Platelet Cyclooxygenase and Lipoxygenase Pathways in Tumor Cell Induced Platelet Aggregation. Biochem Biophys Res Commun 145: 384-389.

12. Best MG, Wesseling P (2018) Tumor-Educated Platelets as a Noninvasive Biomarker Source for Cancer Detection and Progression Monitoring. Cancer Res 78: 3407-3412. [Crossref]

13. Nieswandt B, Hafner M, Echtenacher B, Männel DN (1999) Lysis of Tumor Cells by Natural Killer Cells in Mice Is Impeded by Platelets. Cancer Res 59: 1295-300.

14. Schumacher D, Strilic B, Sivaraj KK, Wettschureck N, Offermanns S (2013) Plateletderived Nucleotides Promote Tumor-Cell Transendothelial Migration and Metastasis via P2Y2 Receptor. Cancer Cell 24: 130-137.

15. Wahrenbrock M, Borsig L, Le D, Varki N, Varki A (2003) Selectin-mucin Interactions as a Probable Molecular Explanation for the Association of Trousseau Syndrome With Mucinous Adenocarcinomas. J Clin Invest 112: 853-62.

16. Barrientos S1, Stojadinovic O, Golinko MS, Brem H, Tomic-Canic M (2008) Growth factors and cytokines in wound healing. Wound Repair Regen 16: 585-601. [Crossref]

17. Kuznetsov HS, Marsh T, Markens BA, Castaño Z, Greene-Colozzi A, et al. (2012) Identification of Luminal Breast Cancers That Establish a Tumor-Supportive Macroenvironment Defined by Proangiogenic Platelets and Bone Marrow-Derived Cells. Cancer Discov 2: 1150-65.

18. Yang AJ, Wang M, Wang Y, Cai W, Li Q, et al. (2018) Cancer Cell-Derived Von Willebrand Factor Enhanced Metastasis of Gastric Adenocarcinoma. Oncogenesis 7: 12 .

19. Yamashita K, Yagi H, Hayakawa M, Abe T, Hayata Y, et al. (2016) Rapid Restoration of Thrombus Formation and High-Molecular-Weight Von Willebrand Factor Multimers in Patients With Severe Aortic Stenosis After Valve Replacement. J Atheroscler Thromb 23: 1150-1158.

20. Sadler JE (2013) Von Willebrand Factor in Its Native Environment. Blood 121: 2583 2584.

21. Yamashita K, Yagi H, Hayakawa M, Abe T, Hayata Y, et al. (2016) Rapid Restoration of Thrombus Formation and High-Molecular-Weight Von Willebrand Factor Multimers in Patients With Severe Aortic Stenosis After Valve Replacement. J Atheroscler Thromb 23: 1150-1158.

22. Dong JF, Moake JL, Nolasco L, Bernardo A, Arceneaux W, et al. (2002) ADAMTS-13 Rapidly Cleaves Newly Secreted Ultralarge Von Willebrand Factor Multimers on the Endothelial Surface Under Flowing Conditions. Blood 100: 4033-4039.

23. Wang Y, Reheman A, Spring CM, Kalantari J, Marshall AH, et al. (2014) Plasma Fibronectin Supports Hemostasis and Regulates Thrombosis. J Clin Invest 124: 42814293.

24. Jain S, Harris J, Ware J (2010) Platelets: Linking Hemostasis and Cancer. Arterioscler Thromb Vasc Biol 30: 2362-2367.

25. Lowe KL, Navarro-Nunez L, Watson SP (2012) Platelet CLEC-2 and Podoplanin in Cancer Metastasis. Thromb Res 129 Suppl 1: S30-S37.

26. Sporn LA, Marder VJ, Wagner DD (1986) Inducible Secretion of Large, Biologically Potent Von Willebrand Factor Multimers. Cell 46: 185-90.

27. Peyvandi F, Garagiola I, Baronciani L (2011) Role of von Willebrand factor in the haemostasis. Blood Transfus 9 Suppl 2: s3-s8. [Crossref]

28. Sonneveld MAH, de Maat MPM, Leebeek FWG (2014) Von Willebrand Factor and ADAMTS13 in Arterial Thrombosis: A Systematic Review and Meta-Analysis. Blood Rev 28: 167-78.

29. Nishio K, Anderson PJ, Zheng XL, Sadler JE (2004) Binding of platelet glycoprotein Ibalpha to von Willebrand factor domain A1 stimulates the cleavage of the adjacent domain A2 by ADAMTS13. Proc Natl Acad Sci US A 101: 10578-10583. [Crossref]

30. Turner N, Nolasco L, Tao Z, Dong JF, Moake J (2006) Human Endothelial Cells Synthesize and Release ADAMTS-13. J Thromb Haemost 4: 1396-404.

31. Levy GG, Motto DG, Ginsburg D (2005) ADAMTS13 turns 3. Blood 106: 11-17. [Crossref]

32. Levy GG, Nichols WC, Lian EC, Foroud T, McClintick JN, et al (2001) Mutations in a Member of the ADAMTS Gene Family Cause Thrombotic Thrombocytopenic Purpura. Nature 413: 488-94.

33. Lopes da Silva M, Cutler DF (2016) Von Willebrand Factor Multimerization and the Polarity of Secretory Pathways in Endothelial Cells. Blood 128: 277-285.
34. Dmitrieva NI, Burg MB (2014) Secretion of Von Willebrand Factor by Endothelial Cells Links Sodium to Hypercoagulability and Thrombosis. Proc Natl Acad Sci U S A 111: 6485-90.

35. Gil-Bazo I, Goni VC, Gutiérrez AA, Rodríguez Rodríguez J, Páramo Fernández JA, et al. (2005) Impact of Surgery and Chemotherapy on Von Willebrand Factor and Vascular Endothelial Growth Factor Levels in Colorectal Cancer. Clin Transl Oncol 7: $150-155$.

36. Koh SCL, Khalil R, Lim FK, Ilancheran A, Choolani M (2006) The Association Between Fibrinogen, Von Willebrand Factor, Antithrombin III, and D-dimer Levels and Survival Outcome by 36 Months From Ovarian Cancer. Clin Appl Thromb Hemost 12: 3-8.

37. Pépin M, Kleinjan A, Hajage D, Büller HR, Di Nisio M, et al. (2016) ADAMTS-13 and Von Willebrand Factor Predict Venous Thromboembolism in Patients With Cancer. $J$ Thromb Haemost 14: 306-315.

38. Yang X, Sun HJ, Li ZR, Zhang H, Yang WJ, et al (2015) Gastric Cancer-Associated Enhancement of Von Willebrand Factor Is Regulated by Vascular Endothelial Growth Factor and Related to Disease Severity. BMC Cancer 15:80.

39. Liu Y, Wang X, Li S, Hu H, Zhang D, et al. (2014) The Role of Von Willebrand Factor as a Biomarker of Tumor Development in Hepatitis B Virus-Associated Human Hepatocellular Carcinoma: A Quantitative Proteomic Based Study. J Proteomics 106: 99-112.

40. Terraube V, Marx I, Denis CV (2007) Role of Von Willebrand Factor in Tumor Metastasis. Thromb Res 120 Suppl 2: S64-S70.

41. Eppert K, Wunder JS, Aneliunas V, Kandel R, Andrulis IL (2005) Von Willebrand Factor Expression in Osteosarcoma Metastasis. Mod Pathol 18: 388-97.

42. Pagliari MT, Lotta LA, Haan HG, Valsecchi C, Casoli G, et al (2016) Next-Generation Sequencing and In Vitro Expression Study of ADAMTS13 Single Nucleotide Variants in Deep Vein Thrombosis. PLoS One 11: e0165665.

43. Kokame K, Matsumoto M, Soejima K, Yagi H, Ishizashi H, et al. (2002) Mutations and Common Polymorphisms in ADAMTS13 Gene Responsible for Von Willebrand Factor-Cleaving Protease Activity. Proc Natl Acad Sci US A 99: 11902-11907.

44. Guo R, Yang J, Liu X, Wu J (2018) Increased von Willebrand factor over decreased ADAMTS-13 activity is associated with poor prognosis in patients with advanced nonsmall-cell lung cancer. J Clin Lab Anal 32. [Crossref]

45. Brinkmann V, Reichard U, Goosmann C, Fauler B, Uhlemann Y, et al (2004) Neutrophil Extracellular Traps Kill Bacteria. Science 303: 1532-1535.

46. Petretto A, Bruschi M, Pratesi F, Croia C, Candiano G, et al. (2019) Neutrophil extracellular traps (NET) induced by different stimuli: A comparative proteomic analysis. PLOS ONE 14: e218946.

47. Cortjens B, van Woensel JB2, Bem RA2 (2017) Neutrophil Extracellular Traps in Respiratory Disease: guided anti-microbial traps or toxic webs? Paediatr Respir Rev 21: 54-61. [Crossref]

48. Laridan E, Martinod K, De Meyer SF (2019) Neutrophil Extracellular Traps in Arterial and Venous Thrombosis. Semin Thromb Hemost 45: 86-93.

49. Brill A, Fuchs TA, Savchenko AS, Thomas GM, Martinod K, et al. (2012) Neutrophil extracellular traps promote deep vein thrombosis in mice. J Thromb Haemost 10: 136-144.

50. Brinkmann V, Zychlinsky A (2012) Neutrophil extracellular traps: is immunity the second function of chromatin? J Cell Biol 198: 773-783.

51. Fuchs TA, Brill A, Duerschmied D, Schatzberg D, Monestier M, et al. (2010) Extracellular DNA traps promote thrombosis. Proc Natl Acad Sci U S A 107: 1588015885. [Crossref]

52. Ammollo CT, Semeraro F, Xu J, Esmon NL, Esmon CT (2011). Extracellular histones increase plasma thrombin generation by impairing thrombomodulin-dependent protein C activation. J Thromb Haemost 9: 1795-1803.

53. 53. Semeraro F, Ammollo CT, Morrissey JH, Dale GL, Friese P, et al. (2011) Extracellular histones promote thrombin generation through platelet-dependent mechanisms: involvement of platelet TLR2 and TLR4. Blood 118: 1952-1961.

54. Wagner DD (2014) Neutrophil Extracellular Traps and von Willebrand Factor in Thrombosis. Blood 124: SCI-SC30.

55. Grassle S, Huck V, Pappelbaum KI, Gorzelanny C, Aponte-Santamaria C, et al. (2014) von Willebrand factor directly interacts with DNA from neutrophil extracellular traps. Arterioscler Thromb Vasc Biol 34: 1382-1389.

56. Monti M, Iommelli F, De Rosa V, Carriero MV, Miceli R, et al. (2017) Integrindependent Cell Adhesion to Neutrophil Extracellular Traps Through Engagement of Fibronectin in Neutrophil-Like Cells. PLoS One 12: e0171362. 
57. Cools-Lartigue J, Spicer J, Najmeh S, Ferri L (2014) Neutrophil Extracellular Traps in Cancer Progression. Cell Mol Life Sci 71: 4179-4194.

58. Monti M, De Rosa V, Iommelli F, Carriero MV, Terlizzi C, et al. (2018) Neutrophil extracellular traps as an adhesion substrate for different tumor cells expressing RGDbinding integrins. Int J Mol Sci 19: 2350.

59. Rayes RF, Mouhanna JG, Nicolau I, Bourdeau F, Giannias B, et al. (2019) Primary Tumors Induce Neutrophil Extracellular Traps With Targetable Metastasis Promoting Effects. JCI Insight 5: e128008.
60. Cools-Lartigue J, Spicer J, McDonald B, Gowing S, Chow S, et al. (2013) Neutrophil Extracellular Traps Sequester Circulating Tumor Cells and Promote Metastasis. J Clin Invest 123: 3446-3458.

61. Demers M, Krause DS, Schatzberg D, Martinod K, Voorhees JR, et al. (2012) Cancers Predispose Neutrophils to Release Extracellular DNA Traps That Contribute to CancerAssociated Thrombosis. Proc Natl Acad Sci U S A 109: 13076-13081.

62. Alflen A, Prüfer S, Ebner K, Reuter S, Lopez PA, et al. (2017) ADAMTS-13 Regulates Neutrophil Recruitment in a Mouse Model of Invasive Pulmonary Aspergillosis. Sci Rep 7: 7184.

Copyright: (C2020 Monti M. This is an open-access article distributed under the terms of the Creative Commons Attribution License, which permits unrestricted use, distribution, and reproduction in any medium, provided the original author and source are credited. 